\title{
Role of cabbeling in water densification in the Greenland Basin
}

\author{
Y. Kasajima ${ }^{1}$ and T. Johannessen ${ }^{1,2}$ \\ ${ }^{1}$ Geophysical Institute, University of Bergen, Allégaten 70, 5007 Bergen, Norway \\ ${ }^{2}$ Bjerkrnes Centre for Climate Research, Allégaten 55, 5007 Bergen, Norway
}

Received: 22 July 2008 - Published in Ocean Sci. Discuss.: 12 September 2008

Revised: 8 December 2008 - Accepted: 2 July 2009 - Published: 14 July 2009

\begin{abstract}
The effects of cabbeling mixing on water mass modification in the Greenland Sea were explored by hydrographic observations across the Greenland Basin in summer 2006. The neutral surface was chosen as a reference frame, and the strength of cabbeling mixing was quantified by the dianeutral velocity magnitude. Active cabbeling spots were detected with the criterion of the velocity magnitude $>1 \mathrm{~m} /$ day, and four active cabbeling areas were identified; the west of Bear Island (SB), the Arctic Frontal Zone (AFZ), the central Greenland Sea (CG) and the western Greenland Sea (WG). The most vigorous cabbeling mixing was found at SB, where warm North Atlantic Water (NAW) mixed with cold water from the Barents Sea, inducing a maximum velocity of $7.5 \mathrm{~m} /$ day and a maximum density gain of $4.7 \times 10^{-3} \mathrm{~kg} / \mathrm{m}^{3}$. At AFZ and $\mathrm{CG}$, the mixing took place between NAW, modified NAW and Arctic Intermediate Water (AIW), and the density gain at these fronts were $1.5 \times 10^{-3} \mathrm{~kg} / \mathrm{m}^{3}$ (AFZ) and $1.3 \times 10^{-3} \mathrm{~kg} / \mathrm{m}^{3}$ (CG). In the western Greenland Sea, the active cabbeling spots were widely separated and mixing appeared to be rather weak, with a maximum velocity of $2.5 \mathrm{~m} /$ day. The mixing source waters at WG were modified NAW, AIW and even denser water, and the density gain in this area was $0.4 \times 10^{-3} \mathrm{~kg} / \mathrm{m}^{3}$. The deepest mixing produced water whose density is equivalent to that of the dense water of the basin, indicating that cabbeling in the western Greenland Sea contributed directly to basin-scale water densification. The water mass modification rate was the highest at AFZ (about 8.0 Sv), suggesting that cabbeling may play an important role in water transformation in the Greenland Basin.
\end{abstract}

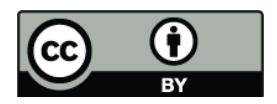

Correspondence to: Y. Kasajima (yoshie.kasajima@gfi.uib.no)

\section{Introduction}

Inter-basin density variation induces water movement from denser to lighter water, and this buoyancy-induced current contributes to the global ocean circulation together with wind-driven currents in the upper layer. Although the global relation between upper and lower currents is not clear, changes in lower layer circulation would influence the upper layer circulation, therefore the investigation of buoyancyinduced currents can be important in a climatological sense. In the northern Atlantic sector, the water in the Nordic Seas is denser than that in the North Atlantic Ocean, and the denser water in the Nordic Seas flows out to the North Atlantic, which is distinguished as a meridional overturning current. The density contrast between the Nordic Seas and the North Atlantic is due to the hydrographic condition of the Greenland Sea, which allows for deep water formation. The cyclonic gyre and winter surface cooling in the central Greenland Sea creates an ideal condition for Deep Convection and the interplay between warm saline North Atlantic inflow and cold less saline water outflow from the Arctic Ocean promotes the formation of Greenland Sea Deep Water. The observations of the last decades, however, indicate that Deep Convection in the central Greenland Sea has weakened. Consequently, the dense water in the Greenland Basin has not been renewed and the temperature of the dense water has increased, which leads to a decrease of the water density (Clarke et al., 1990; Bönisch et al., 1997; Budéus et al., 1998; Jansen and Opheim, 1999; Karstensen et al., 2005). This implies less density contrast between the Nordic Seas and the North Atlantic, retarding the meridional circulation. Although the dense water in the Nordic Seas is fundamental for the buoyancy-induced circulation, the direct contribution to the southward overflow is the intermediate water which is formed through shallow convection, subduction and gradual transformation of Atlantic Water (Hansen and Østerhus, 2000). The formation of intermediate water involves

Published by Copernicus Publications on behalf of the European Geosciences Union. 


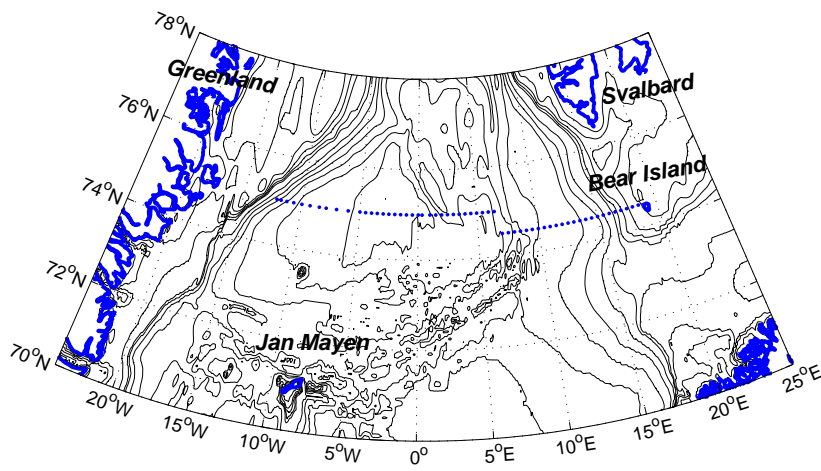

Fig. 1. CTD stations in the study area.

interaction with deep water, and small scale mixing processes play an essential role in the modification of water properties in the whole basin. Small scale mixing is highly localised and the evaluation of its impacts on the global circulation is not an easy task. Nevertheless, it is important to investigate the effects of small scale mixing on water modification and subsequent change of the overall hydrographic condition, especially when deep convection weakens.

Mechanical turbulent mixing is generally the most robust mixing process. Its principal source is external forces such as wind and tides, and turbulence by wind and tides homogenises the upper layer. Wind- and tidal-induced internal waves are important agents for deep water modification by enhancing turbulent mixing in the ocean interior. The contribution of turbulent mixing to buoyancy change is represented in terms of the vertical diffusivity. Munk and Wunch (1998), however, found that turbulent mixing alone is not enough to balance the global upwelling and claimed that including all significant turbulent mixing spots in the deep ocean was required for a proper estimation of diffusivity. Further investigation of significant turbulent mixing spots in the deep ocean is necessary, though the insufficiency of turbulent mixing implies that the contribution of other mixing processes can be substantial in the basin scale change of buoyancy.

Apart from turbulent mixing, important small scale mixing processes include double diffusion, cabbeling and thermobaricity. The driving force of double diffusion is the difference in the molecular diffusivity of heat and salt. Temperature diffuses much faster than salt and thus a water parcel loses heat quickly while salinity remains nearly unchanged, and the density of the water parcel changes without external forcing. Cabbeling and thermobaricity occur due to the nonlinear features of seawater. The first is a mixing of water masses with different properties, which produces water denser than source waters, and the second is the densification of a water parcel as a result of compressibility where cold water is more compressible than warm water. In high latitudes, the presence of sea ice cools surface waters nearly to the freezing point and can create a sharp interface in the sur- face layer between cold less saline water on top and warmer and saline water below. This is a prerequisite for double diffusive convection, and the strong stratification can cause an abrupt overturning though thermobaricity (Akitomo, 1999). In the Barents Sea, double diffusive mixing plays an important role when the shear-induced turbulent mixing is relatively weak (Sundfjord et al., 2007). At the Arctic Front to the west of Spitsbergen, warm and saline North Atlantic Water and cold and less saline Arctic Water create an ideal hydrographic condition for double diffusion and cabbeling processes (Cottier and Venables, 2007).

McDougall (1987a) derived a water mass modification equation for turbulent mixing, double diffusion, cabbeling, and thermobaricity and estimated that cabbeling and thermobaric processes in the North Atlantic would cause watermass conversion of a magnitude equal to that caused by a vertical diffusivity of $10^{-4} \mathrm{~m}^{2} \mathrm{~s}^{-1}$. A theoretical study by Garrett and Horne (1978) exhibited that cabbeling processes caused a significant sinking rate at fronts and may drive vertical circulations to maintain fronts against diffusion. Horne (1978) showed that cabbeling was the dominant mechanism which drove vertical circulation at the subsurface front between warm slope water and Labrador slope water, and You (1996) demonstrated that the contribution of cabbeling together with thermobaricity was significant for vertical transport in the Indian Ocean. At the Antarctic Polar Frontal Zone, cabbeling mixing plays an important role in a strong cross-frontal exchange (Gordon et al., 1977; You, 1999) and it also can cause a significant diapycnal volume flux (Marsh, 2000). In the western Pacific, cabbeling in combination with double diffusion is the major mechanism for water transformation in the subarctic front (Talley and Yun, 2001).

The purpose of this paper is to investigate the role of cabbeling in water densification in the Greenland Basin. In the following sections, we discuss hydrographic conditions and dominant water types in the Greenland Basin (Sect. 2) and review the water mass modification equation presented in terms of the neutral surface coordinate (Sect. 3). In Sect. 4, the significant cabbeling mixing areas are determined from the cabbeling-induced vertical velocity and the water mass modification in the active cabbeling areas are examined, then the density increase due to cabbeling is quantified. The potential contribution of cabbeling to the large scale dynamics is discussed in Sect. 5.

\section{Hydrography}

In July 2006 hydrographic observations were performed from R/V G.O.Sars under the EU-project CARBOOCEAN. The observations were carried out across the Greenland Basin with $34 \mathrm{CTD}$ stations along $75^{\circ} \mathrm{N}$ in the central Greenland Sea and $24 \mathrm{CTD}$ stations along $74.5^{\circ} \mathrm{N}$ on the basin slope towards Bear Island (Fig. 1). 


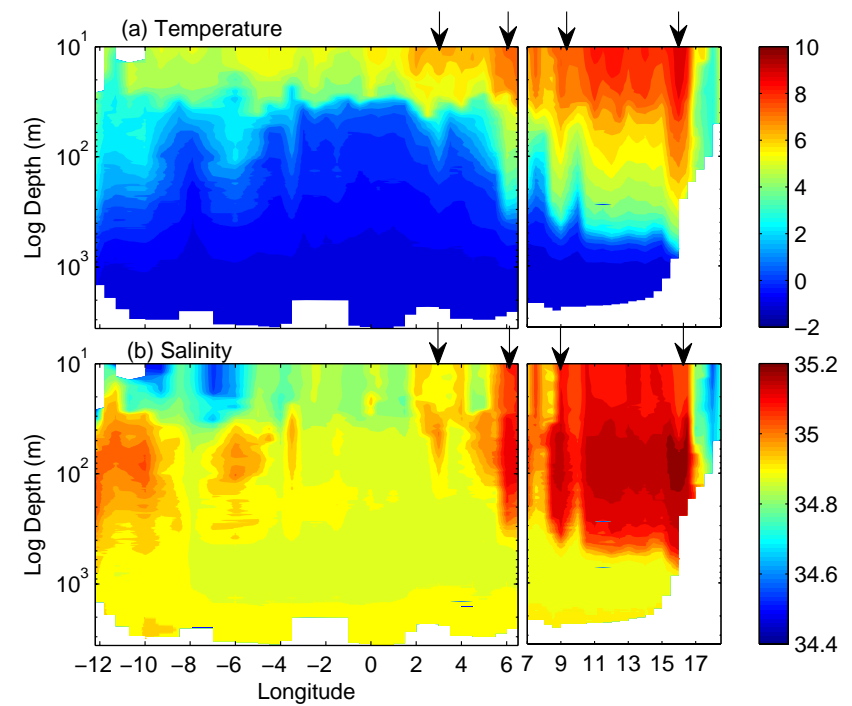

Fig. 2. (a) Temperature and (b) salinity across the Greenland Basin. The upper part is expanded and arrows indicate the frontal interfaces according to van Aken et al. (1991).

CTD observations show the general hydrographic features in the Greenland Sea; warm Atlantic water flows northward in the east, cold less saline water is found in the central part, fresh water in the western surface layer and the re-circulated Atlantic water below the fresh water (Fig. 2). The dominant water type in the east, North Atlantic Water (NAW), is found in the upper $500 \mathrm{~m}$ with a salinity above 35 . Within the dominant NAW, two NAW cores ( $\mathrm{S}>35.1$ ), can be identified; one is around $16^{\circ} \mathrm{E}$ and another around $9^{\circ} \mathrm{E}$ and a cold water column around $10^{\circ} \mathrm{E}$ separates these two cores. Further west, there is another saline water column around $6^{\circ} \mathrm{E}$ and a saline water patch around $3^{\circ} \mathrm{E}$, which is a forefront of NAW in the eastern Greenland Sea. The area with significant horizontal property gradients due to NAW is distinguished as the Arctic Frontal Zone. According to observations along $74.45^{\circ} \mathrm{N}$ in February 1989 there are four frontal interfaces in the Arctic Frontal Zone (van Aken et al., 1991). The locations of these frontal interfaces agree well with our observations, except the easternmost front which is located slightly to the west around $10^{\circ} \mathrm{E}$. These frontal interfaces are named front A, B, C and D (Fig. 2) following van Aken et al. (1991). In the western part, the re-circulated NAW occupies depths from near surface to about $400 \mathrm{~m}$ and the salinity is comparable to that of NAW in the eastern part. Low salinity water in the surface layer is rather insignificant in 2006. On the easternmost part of the basin, there is another water type of less saline and cold water. It creates a sharp interface with NAW and can be identified as Spitsbergen Bank Water (SBW, Loeng, 1990). SBW is formed locally in the Barents Sea and the sharp interface with NAW can be the westward continuation of the front which is formed along the Spitsbergen Bank.
Table 1. Water mass classification in the Greenland and Iceland Seas according to Swift and Aagaard (1981); NAW, PW, uAIW, 1AIW, NSDW, GSDW, van Aken et al. (1995); NwAW, Atlantic Water type, Loeng (1990); SBW. NAW is referred as Atlantic Water (AW) in Swift and Aagaard (1981).

\begin{tabular}{lll}
\hline Water type & $\mathrm{S}$ & $\theta$ \\
\hline Atlantic Water (AW) & $35.1<\mathrm{S}<35.3$ & $6<\theta<8$ \\
$\quad$ Norwegian Atlantic Water (NwAW) & $35.0<\mathrm{S}$ & $3<\theta$ \\
$\quad$ Atlantic Water type & $34.9<\mathrm{S}$ & $2<\theta$ \\
Polar Water (PW) & $\mathrm{S}<34.4$ & $\theta<0$ \\
Upper Arctic Intermediate Water (uAIW) & $34.9<\mathrm{S}<35.0$ & $0<\theta<3$ \\
Lower Arctic Intermediate Water (lAIW) & $34.7<\mathrm{S}<34.9$ & $\theta<2$ \\
Norwegian Sea Deep Water (NSDW) & $34.90<\mathrm{S}<34.94$ & $\theta<0$ \\
Greenland Sea Deep Water (GSDW) & $34.88<\mathrm{S}<34.90$ & $\theta<-1$ \\
Spitsbergen Bank Water (SBW) & $\mathrm{S}<34.4$ & $1<\theta<3$ \\
\hline
\end{tabular}

The water masses in the Greenland Sea were classified by Swift and Aagaard (1981) and they are listed in Table 1. The hydrographic data in 2006 are compared to their definitions on a T-S diagram (Fig. 3). The dataset in 2006 shows that Greenland Sea Deep Water (GSDW) is absent and that the densest water, which is less than $\sigma_{\theta}=28.1$, is classified as Norwegian Sea Deep Water (NSDW). Polar Water is not present. Instead very low salinity water $(<33.0)$ is present, corresponding to SBW. The salinity of NAW is more than 35.1 according to Swift and Aagaard (1981), though most of the NAW shown in Fig. $2 b$ tends to be less saline and colder. Van Aken et al. (1991) refers to water of Atlantic origin as the Atlantic water type $\left(\mathrm{S}>34.9\right.$ and $\left.\theta>2{ }^{\circ} \mathrm{C}\right)$, and NAW properties in the Norwegian Sea is defined as $\theta>3^{\circ} \mathrm{C}, \mathrm{S}>35.0$, which is referred as Norwegian Atlantic Water (NwAW) in van Aken et al. (1995). Their definition matches better to NAW property in 2006. SBW properties in 2006 are also different from the definition of Loeng (1990), having become slightly warmer and more saline.

The lack of GSDW and the discrepancy in water properties from the definition of Swift and Aagaard (1981) indicates that water properties in the Greenland Basin have changed through decades, therefore, we re-define water types as a matter of convenience based on the water types listed in Table 1. The temperature and salinity range of Atlantic Water type is broader than that of NAW and it can be applied to NAW in 2006, however, the salinity of re-circulated NAW on the west is as high as that of NAW in the east. In order to separate NAW from the re-circulated NAW we define NAW to have $\mathrm{S}>34.9$ and $\theta>3^{\circ} \mathrm{C}$ while the re-circulated NAW is colder than $3^{\circ} \mathrm{C}$. According to this definition the re-circulated NAW can include colder NAW in the eastern Greenland Sea, therefore this water type is called modified NAW (mNAW). The temperature and salinity ranges of SBW are expanded and the water is re-named as Bear Island Water (BIW). Water corresponding to NSDW property is re-named as Dense Water (DW). The interior water in the Greenland Basin is 


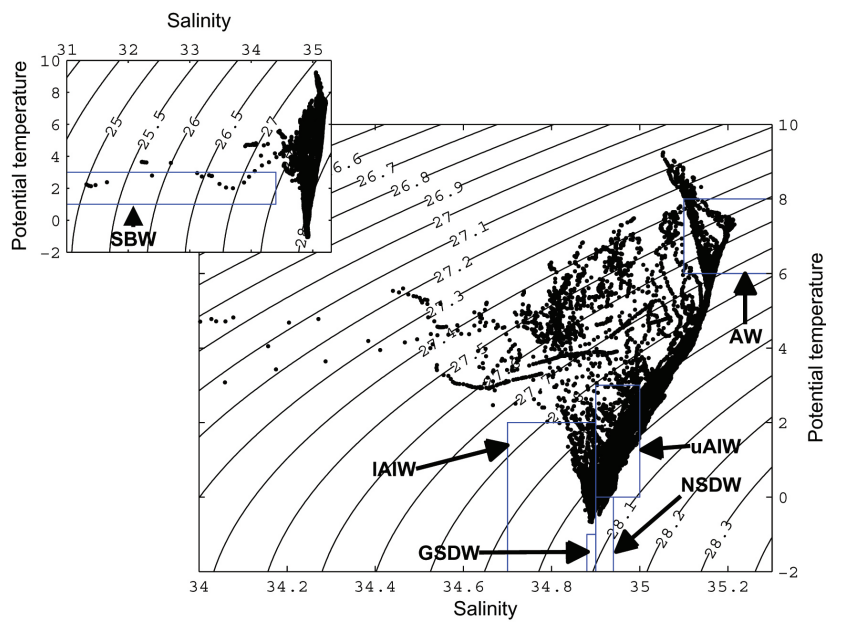

Fig. 3. T-S diagram for all data points (upper small diagram) and for more focused data points (large). Water types defined by Swift and Aagaard (1981) are indicated with boxes in the large diagram.

classified as Arctic Intermediate Water (AIW), which is less saline than NAW and warmer than DW. These re-defined water properties are listed in Table 2 together with their volume percentages.

The re-defined water types occupy about $70 \%$ of the volume in the cross-section and the rest can be thought as a mixture of the defined waters. Within the defined water types, DW accounts for the largest part $(\sim 54 \%)$ and the percentage of NAW, mNAW, AIW and BIW together is less than half of that of DW (about 16\%). The high density in the Greenland Basin is due to the large volume of DW and an additional $30 \%$ of the total water volume, which is not classified into water types listed in Table 2, has low temperature with density close to DW (Fig. 3). These dense waters determine the overall density of the Greenland Basin. Even though the volume is small, these mixed water types are an important source for heat and salt in the Greenland Basin and also for DW property change in the long term.

\section{Water mass modification equation}

The neutral surface, which is a surface satisfying the relation (McDougall, 1987b),

$\alpha \nabla_{n} \theta=\beta \nabla_{n} S$.

is used as the coordinate system in this study. $\alpha$ and $\beta$ are the thermal expansion and haline contraction coefficients defined as (for the definition of $\alpha^{\prime}$ and $\beta^{\prime}$, see Gill, 1982)

$$
\begin{aligned}
& \alpha=-\left.\frac{1}{\rho} \frac{\partial \rho}{\partial \theta}\right|_{S, p}=\alpha^{\prime}\left[\left.\frac{\partial \theta}{\partial T}\right|_{S, p}\right]^{-1} \\
& \beta=-\left.\frac{1}{\rho} \frac{\partial \rho}{\partial S}\right|_{\theta, p}=\beta^{\prime}+\left.\alpha \frac{\partial \theta}{\partial S}\right|_{T, p}
\end{aligned}
$$

Table 2. Water types found in the current dataset. The relative volume percentage is calculated by data points which satisfy the salinity temperature range for water types divided by the total data number times 100 .

\begin{tabular}{llll}
\hline Water type & Salinity & $\begin{array}{l}\text { Potential } \\
\text { temperature }\end{array}$ & $\begin{array}{l}\text { Relative } \\
\text { volume } \\
\text { percentage }\end{array}$ \\
\hline $\begin{array}{l}\text { North Atlantic } \\
\begin{array}{l}\text { Water (NAW) } \\
\text { Modified North }\end{array}\end{array}$ & $34.9<\mathrm{S}$ & $3<\theta$ & $5.8 \%$ \\
$\begin{array}{l}\text { Atlantic Water } \\
\text { (mNAW) }\end{array}$ & $34.9<\mathrm{S}$ & $0<\theta<3$ & $7.5 \%$ \\
$\begin{array}{l}\text { Arctic Intermediate } \\
\text { Water (AIW) }\end{array}$ & $34.7<\mathrm{S}<34.9$ & $\theta<2$ & $1.9 \%$ \\
$\begin{array}{l}\text { Dense Water (DW) } \\
\text { Bear Island Water } \\
\text { (BIW) }\end{array}$ & $34.90<\mathrm{S}<34.94$ & $\theta<0$ & $53.4 \%$ \\
\hline
\end{tabular}

and $\nabla_{n}$ is the lateral gradient operator along a neutral surface. The neutral surface allows a water parcel to move without experiencing a buoyancy restoring force along the surface, whereas on an isopycnal surface the restoring force becomes significant with distance from the reference level due to the effect of compressibility. Therefore, the neutral surface frame is more appropriate for the study of lateral mixing. In the analysis domain, neutral surfaces are calculated eastward from the points with certain density $\left(\sigma_{\theta}=27.50\right.$, $27.51, \ldots 28.07$ with the interval of 0.01$)$ in the westernmost station and 58 neutral surfaces $(\gamma 27.50, \gamma 27.51, \ldots, \gamma 28.07)$ are determined. When a neutral surface outcrops it cannot be traced further since the water properties are not conserved along a neutral surface. In the study area, $\gamma 27.50-\gamma 27.55$ outcrops already by $10.7^{\circ} \mathrm{W}$, and $\gamma 27.56$ by $2^{\circ} \mathrm{W}$, therefore only water properties below $\gamma 27.56$ are analysed across the whole basin.

Selected neutral surfaces and their isopycnal counterparts, potential density referenced to the surface, are shown in Fig. 4. The deviation between neutral surfaces and the isopycnals becomes notable with depth and tends to be larger toward the eastern periphery. Neutral surfaces appear shallower than isopycnals and the difference tends to be conspicuous in the middle of the Greenland Basin, in which $\gamma 28.07$ appears around $1500 \mathrm{~m}$ while $\sigma_{\theta}=28.07$ appears at nearly $1800 \mathrm{~m}$. The deeper location of isopycnals causes higher pressure gradients along the isopycnals that would lead to erroneous lateral mixing (McDougall, 1987b). The neutral layers above $\gamma 28.0$ are confined in shallow waters in the central Greenland Sea while layers from $\gamma 28.0$ to $\gamma 28.07$ occupy most of the spatial domain $(100 \mathrm{~m}-1500 \mathrm{~m})$. Along $74.5^{\circ} \mathrm{N}$, the neutral surfaces are spaced more evenly and the vertical distance between $\gamma 28.0$ and $\gamma 28.07$ decreases to $150 \mathrm{~m}$ in the eastern periphery. The thickness from $\gamma 28.0$ to $\gamma 28.07$ can be interpreted as the thickness of the intermediate water 


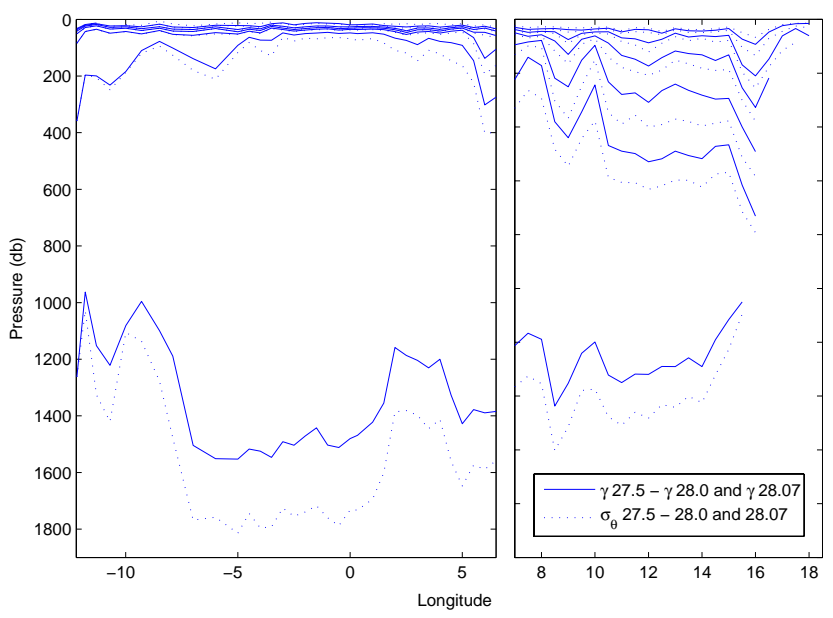

Fig. 4. Neutral surfaces (solid lines) and isopycnals referenced to surface (dotted lines) across the Greenland Basin. Neutral surfaces are at 27.6, 27.7, 27.8, 27.9, 28.0 and 28.07 calculated eastward from the western-most station. The shallowest neutral surface, $\gamma 27.5$, outcrops to the west of $10.7^{\circ} \mathrm{W}$ and therefore does not appear in the figure.

layer and $\gamma 28.07$ can correspond to the permanent pycnocline which separates the intermediate water from the deep water in the basin. The analysis domain in this study represents the surface and intermediate layers.

McDougall (1984, 1987a) formulated an equation for $e$, the vertical velocity associated with turbulence, double diffusion, cabbeling and thermobaricity from the conservation equations for heat and salt. It is expressed as,

$$
\begin{aligned}
& \left(e-D_{z}\right) g^{-1} N^{2}=D\left(\alpha \theta_{z z}-\beta S_{z z}\right)+\left(\beta F_{z}^{S}-\alpha F_{z}^{\theta}\right) \\
& -\kappa\left\lfloor\theta_{z} C_{c b}\left|\nabla_{n} \theta\right|^{2}+\theta_{z} C_{t h} \nabla_{n} \theta \cdot \nabla_{n} p\right\rfloor
\end{aligned}
$$

Here $\kappa$ and $D$ indicate the epineutral and dianeutral diffusion coefficients, $R_{\rho}=\alpha \theta_{z} / \beta S_{z}$ is a density ratio and $F^{\theta}, F^{s}$ are the double diffusive fluxes of heat and salinity.

$C_{c b}$ and $C_{t h}$ are cabbeling and thermobaric parameters, expressed as

$$
\begin{aligned}
& C_{c b}(\theta, S, p)=\left[\frac{\partial \alpha}{\partial \theta}+2 \frac{\alpha}{\beta} \frac{\partial \alpha}{\partial S}-\frac{\alpha^{2}}{\beta^{2}} \frac{\partial \beta}{\partial S}\right], \\
& C_{t h}(\theta, S, p)=\left[\frac{\partial \alpha}{\partial p}-\frac{\alpha}{\beta} \frac{\partial \beta}{\partial p}\right] .
\end{aligned}
$$

The terms on the right side of (2) indicate turbulent mixing, double diffusive mixing, and non-linear processes (cabbeling and thermobaricity). The vertical velocity, $e$, is the result of these mixing processes and the velocity due to the cabbeling process only is written as

$$
e_{c b}=-g N^{-2} \kappa\left|\nabla_{n} \theta\right|^{2} C_{c b}(\theta, S, p) .
$$

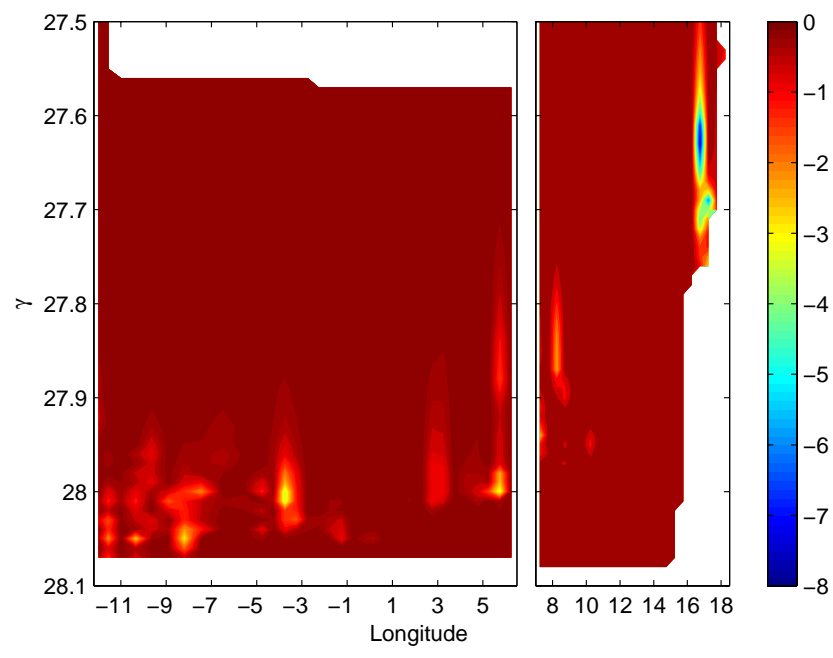

Fig. 5. Cabbeling-induced velocity in the neutral surface domain (m/day).

The cabbeling-induced velocity ( 3 ) is used as an indicator of the strength of the cabbeling mixing and the cabbeling process is investigated based on the velocity in the next section.

Prior to the quantitative study of cabbeling, the effective diffusivity due to cabbeling is calculated in order to see the significance of cabbeling in the study area. The effective diffusivity is equivalent to the vertical diffusivity that will cause the same vertical velocity calculated from (2), and it is (McDougall, 1987a)

$D_{c b}=\kappa\left|\nabla_{n} \theta\right|^{2} C_{c b}(\theta, S, p) /\left(\alpha \theta_{z z}-\beta S_{z z}\right)$.

Using the lateral diffusivity $\kappa=550 \mathrm{~m}^{2} \mathrm{~s}^{-1}$ estimated from the tracer release experiment in the central Greenland Sea (Messias et al., 2007), the effective diffusivity averaged over the whole Greenland Sea is $D_{c b}=3.4 \times 10^{-6} \mathrm{~m}^{2} \mathrm{~s}^{-1}$. This is not very significant, however the spatial variation in the diffusivity is large and the maximum $D_{c b}$ exceeds $0.1 \mathrm{~m}^{2} \mathrm{~s}^{-1}$. It is expected that cabbeling plays an important role in the local mixing in certain areas even though the spatial average of cabbeling effects can be rather insignificant.

\section{Cabbeling mixing in the Greenland Basin}

\subsection{Cabbeling-induced velocity}

As the effective diffusivity indicates, cabbeling mixing is highly localised like other small scale mixing, and the effects of cabbeling are evaluated by exploring the active cabbeling spots. The magnitude of the dianeutral velocity, $e_{c b}$, can be a good indicator for active mixing. The velocity across the Greenland Basin shows that high velocity patches appear intermittently but their locations seem to be consistent with the interfaces of different water types (Fig. 5). The highest velocity over the whole area is found in the eastern periphery, 


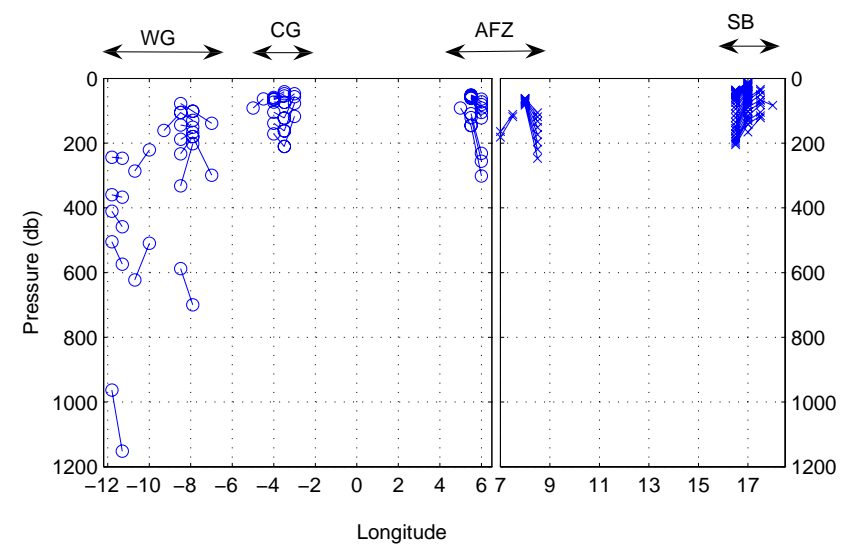

Fig. 6. Active cabbeling mixing areas in the pressure-longitude domain. Mixing which generates velocities greater than $1 \mathrm{~m} /$ day is shown with its source water locations connected with a line. The mixing areas are distinguished as $\mathrm{SB}, \mathrm{AFZ}, \mathrm{CG}$ and $\mathrm{WG}$ as indicated on the top.

where the high velocity appears as a columnar structure from surface to bottom. It corresponds to the interface between BIW and NAW and the velocity maximum is found around $\gamma 27.65$ with the highest magnitude of $7.5 \mathrm{~m} /$ day. In the Arctic Frontal Zone $\left(2^{\circ} \mathrm{E} \sim 15^{\circ} \mathrm{E}\right)$ the high velocity patches appear around $10^{\circ} \mathrm{E}, 8^{\circ} \mathrm{E}$ and $6^{\circ} \mathrm{E}$, which are consistent with the locations of the frontal interfaces. The highest velocity is around $\gamma 28.0$ at front $\mathrm{B}\left(\right.$ at $\left.6^{\circ} \mathrm{E}\right)$ and its magnitude reaches $3 \mathrm{~m} /$ day. The velocity patch shifts position to lower layers in the neutral surface coordinate towards the west, and it is seen at $\gamma 28.0$ with the magnitude of $4 \mathrm{~m} /$ day in the central basin. Further west, the high velocity patch is more widely spread over the area below $\gamma 28.0$, and the velocity is rather low with a maximum value of less than $3 \mathrm{~m} /$ day. The velocity patches are not seen in the vast area above $\gamma 27.7$ in the western and central Greenland Sea, and below $\gamma 27.8$ in the eastern periphery.

Garrett and Horne (1978) showed that the typical cabbeling-induced vertical velocity at a front was $1 \mathrm{~m} /$ day, and this value is used as the criterion of active cabbeling mixing. Figure 6 shows the geographical location of the mixing spots which pass this criterion and the two points connected with a line indicate the positions of the mixing source waters. As shown in Fig. 6, the active cabbeling spots are found in the eastern periphery, the Arctic Frontal Zone, the central and the western Greenland Sea. These areas are recognised as frontal areas and are referred to as SB, AFZ, CG and WG, respectively. $\mathrm{SB}, \mathrm{AFZ}$ and $\mathrm{CG}$ are located in the surface layer or in the upper part of the intermediate layer and their extensions in space are rather small, whereas cabbeling spots at WG are interspersed over the intermediate layer, even at the edge of the permanent pycnocline (see Fig. 4). The zonal and vertical extensions of fronts are listed in Table 3.
Table 3. The areas of high cabbeling mixing. SB is west of Bear Island, AFZb-c are in the Arctic Frontal Zone, CG located in the central Greenland Sea, WG is in the western Greenland Sea.

\begin{tabular}{|c|c|c|c|}
\hline $\begin{array}{l}\text { Front } \\
\text { name }\end{array}$ & $\begin{array}{l}\text { Horizontal } \\
\text { range }\end{array}$ & $\begin{array}{l}\text { Depth } \\
\text { range }\end{array}$ & $\begin{array}{l}\text { Volume of the front } \\
\text { per } \mathrm{m} \text { of meridional } \\
\text { extent }\left(\times 10^{6} \mathrm{~m}^{3}\right)\end{array}$ \\
\hline SB & $\begin{array}{l}16.5-18.5 \mathrm{E} \\
(59.4 \mathrm{~km})\end{array}$ & $\begin{array}{l}13-205 \mathrm{~m} \\
(193 \mathrm{~m})\end{array}$ & 11.5 \\
\hline $\begin{array}{l}\text { AFZ } \\
\text { AFZc } \\
\text { AFZb }\end{array}$ & $\begin{array}{l}8-8.5 \mathrm{E} \\
5-7.5 \mathrm{E} \\
(116.4 \mathrm{~km})\end{array}$ & $\begin{array}{l}62-245 \mathrm{~m} \\
51-302 \mathrm{~m} \\
(252 \mathrm{~m})\end{array}$ & 29.3 \\
\hline $\mathrm{CG}$ & $\begin{array}{l}5-3 \mathrm{~W} \\
(57.5 \mathrm{~km})\end{array}$ & $\begin{array}{l}41-210 \mathrm{~m} \\
(170 \mathrm{~m})\end{array}$ & 9.8 \\
\hline WG & $\begin{array}{l}12-7 \mathrm{~W} \\
(143.8 \mathrm{~km})\end{array}$ & $\begin{array}{l}78-1152 \mathrm{~m} \\
(1075 \mathrm{~m})\end{array}$ & 154.6 \\
\hline
\end{tabular}

According to the Eq. (3), the cabbeling velocity is determined by three factors, i.e. the stratification, the lateral temperature gradient, and the cabbeling parameter, and the magnitude of the cabbeling velocity is the result of the balance between these parameters. In this study the variation in the cabbeling parameter is small $\left(1.2 \sim 1.3 \times 10^{-5 \circ} \mathrm{C}^{-2}\right)$ and its effect on the velocity magnitude is minor. The buoyancy frequency and the lateral temperature gradient are the competing factors but buoyancy frequency seems to dominate over lateral temperature gradient. The Arctic Frontal Zone is an area of high lateral temperature gradient, though the active cabbeling spots are found only at front $\mathrm{B}$ and front $\mathrm{C}$. The buoyancy frequency (Fig. 7) shows that the active cabbeling spots appear below $1.0 \times 10^{-4} \mathrm{~s}^{-1}$, below the pycnocline $(\sim 50 \mathrm{~m})$. The cabbeling spots at front $\mathrm{A}$ and front $\mathrm{D}$ are located in the stratified layers, and thus the vertical velocity at these fronts would be suppressed by the high stratification. In the other highly stratified area active cabbeling is not seen, either.

\subsection{Water modification at frontal areas}

The vertical velocity causes a dianeutral flux associated with water mass modification, which induces water volume changes within layers where mixing takes place. In order to understand where and by how much source waters change their properties the water mass formation rate is calculated. The water mass formation rate, $M(\gamma)$, is defined by the volume flux change through the isopycnals (Walin, 1982),

$M(\gamma)=\partial G(\gamma) / \partial \gamma$.

Here $G(\gamma)$ is the volume flux across the vertical coordinate $\gamma$. Our observations are spatially limited and cannot provide a precise volume transport per unit area. In order to apply 


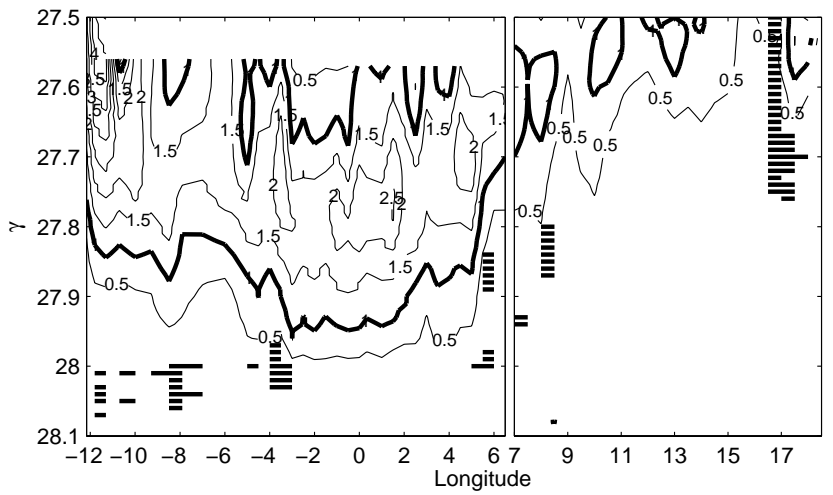

Fig. 7. Buoyancy frequency $\left(\times 10^{-4} \mathrm{~s}^{-1}\right)$ and the areas in which cabbeling-induced velocity is more than $1 \mathrm{~m} /$ day. The thick lines indicate $N^{2}=1.0 \times 10^{-4} \mathrm{~s}^{-1}$.

Eq. (5) and to examine the mixed water properties, we make a few assumptions about the velocity and the size of the fronts. Firstly, the velocity at the active cabbeling spots at each front is averaged over each neutral surface and this averaged velocity represents the cabbeling velocity at the frontal area. Secondly, the frontal area is defined by the zonal length of fronts listed in Table 3. The meridional length of fronts is taken as $1 \mathrm{~km}$ since measurements along a section preclude any knowledge of the meridional extent of a cross-section front. Volume fluxes should, under this assumption, be understood as volume fluxes per kilometre of meridional front extent, with a similar understanding applied to formation rates as well. The realistic meridional length of the front can be much larger, and the zonal length would be much smaller since the active cabbeling spots are interspersed within the zonal space. The more realistic horizontal front size is discussed in the last section. The assumed frontal area in this section is then $59.4 \mathrm{~km}^{2}$ for $\mathrm{SB}, 116.4 \mathrm{~km}^{2}$ for AFZ, $57.5 \mathrm{~km}^{2}$ for CG and $143.8 \mathrm{~km}^{2}$ for WG. We express the volume flux such that $G(\gamma)=e_{c b}(\gamma) \times A$ (units of $\mathrm{m}^{3} \mathrm{~s}^{-1}$ ), where the vertical coordinate $\gamma$ is associated with neutral surfaces instead of isopycnals in this study. Lastly, the volume flux through the lowest neutral surface is calculated by assuming that the velocity at the layer below is zero. The water mass formation rate $M(\gamma)$ is quantified at the layer between the neutral surface $\gamma_{i}$ and $\gamma_{i+1}$. We also assume that cabbeling in the study area takes place without mechanical forcing and that the adjacent water masses along the neutral surface mixes in equal proportions. The source water properties at each frontal area are shown in the TS-diagrams (Fig. 8), where the mixed water properties are expected to lie halfway between the two source water properties.

Figure 9 shows the vertical variation of the cabbeling velocity of Fig. 5, evaluated here over the extent of each front. The velocity at SB is the highest of all. On the other hand, the local maxima are not so sharp at the other fronts where the vertical variation in the velocity magnitude is rather small. The cabbeling spots at AFZ are categorized in three differ-
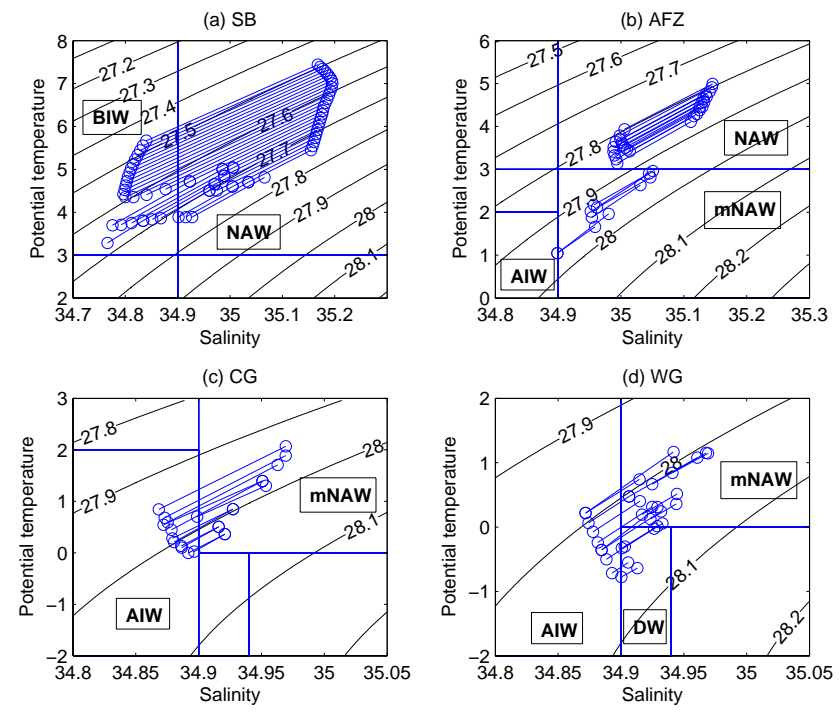

Fig. 8. T-S diagrams of mixing source water at (a) SB, (b) AFZ, (c) CG and (d) WG. Two end-members are connected with a line and the mixed water property is assumed to lie in the middle of the line.

ent neutral surface ranges; $\gamma 27.8-\gamma 27.89, \gamma 27.93-\gamma 27.94$ and $\gamma 27.98-\gamma 28.0$. The first group in the shallowest layers $(\gamma 27.8-\gamma 27.9)$ stretches over to the whole AFZc and the upper part of AFZb (see Table 3) and the second and third groups corresponds to the lower part of AFZb. The regions of velocity associated with active cabbeling at $C G$ is found on lower neutral surfaces than the second group at AFZ, though its depth is shallower since the neutral surfaces rise to the surface in the central Greenland Sea. At WG the velocity maximum appears at $\gamma 28.05$ in the intermediate layer.

The TS-diagram (Fig. 8a) shows that the source waters at SB are BIW and NAW and all resultant water is classified into NAW. At AFZ (Fig. 8b) there are two types of mixing: one within NAW at a shallow level and another within mNAW, or with AIW at a lower level. The source waters in the first velocity group are clearly distinguished as NAW. The distinction of the source waters for the second and third groups is more complicated: the source waters for the second group are mNAW, and that for the third group are both mNAW and AIW. The resultant water for both the second and third groups is mNAW. The source waters at CG (Fig. 8c) are AIW and mNAW, and mixing of equal proportions of these waters produces mNAW, though its temperature is lower here than that at AFZ. The mixing at WG (Fig. 8d) is the most variable of all the frontal areas and the cabbeling spots at WG are largely interspersed from $80 \mathrm{~m}$ to $1000 \mathrm{~m}$ even though the neutral surface is concentrated in the range between $\gamma 28.0$ $\gamma 28.07$, and the source waters vary in mNAW, AIW and DW. Mixing in the upper neutral layers occurs between mNAW and AIW or within mNAW. In the layer below mNAW the mixing occurs between AIW and DW or within DW. The resultant waters of the mixing at WG are not only of one type but are dependent on the source waters. 

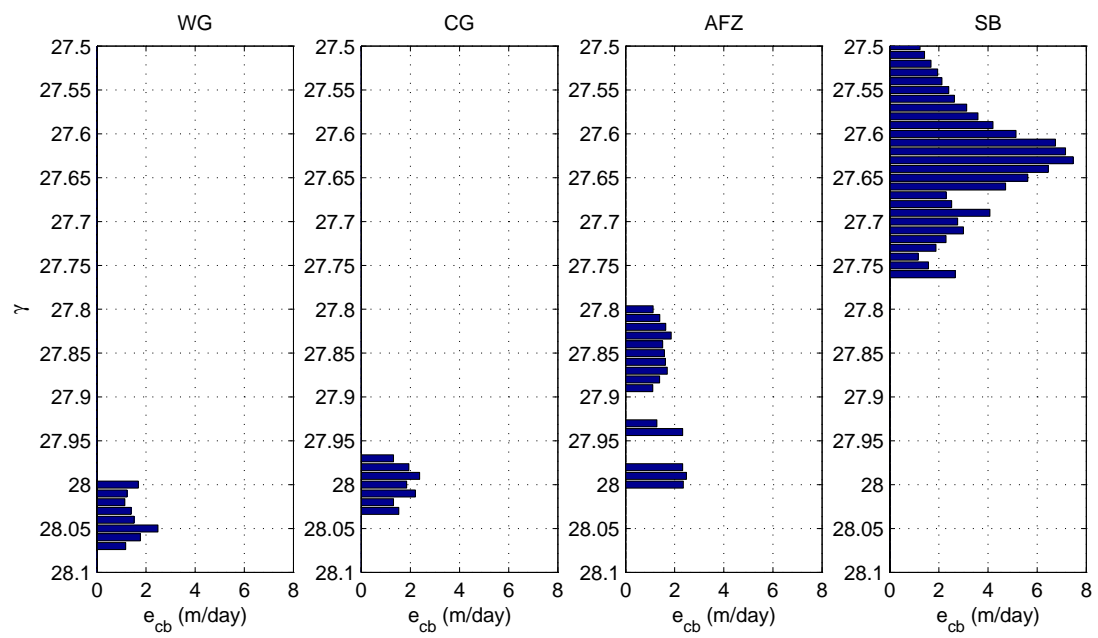

Fig. 9. Velocity $e_{c b}(\gamma)(\mathrm{m} / \mathrm{day})$, averaged over layers.
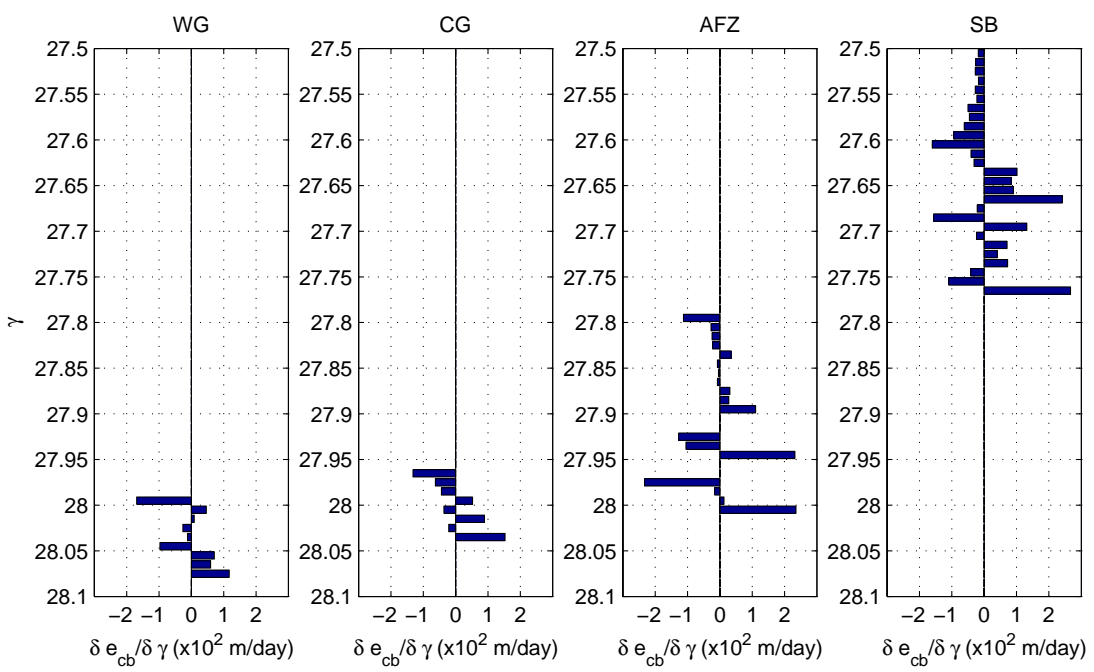

Fig. 10. Vertical velocity divergence ( $\mathrm{m} /$ day), which is equivalent to water mass formation rate per $\mathrm{m}^{2}$.

Figure 10 shows the velocity divergence with respect to the dianeutral direction. If the horizontal frontal area, $A$, is constant, the vertical variation of the velocity divergence is analogous to the vertical variation of the water mass formation rate. The uppermost layer tends to have the highest reduction and the lowermost layer has the highest formation. The sign of the divergence tends to change from negative in the upper layers to positive in the lower layers. The negative (positive) divergence indicates the reduction (formation) of water within the layer, and thus indicates that cabbeling produces denser water in the upper layers and transports it to the lower layers. At SB the highest water volume reduction occurs not in the upper most layer but at $\gamma 27.61$ and the sign of the divergence changes at the local velocity maxima (see Fig. 9). The highest divergence is seen in the lowest layer with the value of $267 \mathrm{~m} /$ day $(\sim 0.0031 \mathrm{~m} / \mathrm{s})$. At AFZ, three pairs of layers of destruction and formation are apparent in $\gamma$-space. The velocity divergence in the lower layer of each pair is $110 \mathrm{~m} /$ day $(\sim 0.0013 \mathrm{~m} / \mathrm{s})$ at $\gamma 27.895,232 \mathrm{~m} /$ day $(\sim 0.0027 \mathrm{~m} / \mathrm{s})$ at $\gamma 27.945$ and $235 \mathrm{~m} /$ day $(\sim 0.0027 \mathrm{~m} / \mathrm{s})$ at $\gamma 28.005$. The divergence maximum at CG is slightly less than that at AFZ $(153 \mathrm{~m} /$ day $\sim 0.0018 \mathrm{~m} / \mathrm{s})$ and it is even smaller at WG $(117 \mathrm{~m} /$ day $\sim 0.0014 \mathrm{~m} / \mathrm{s})$. The positive divergence at $\gamma 28.0$ at WG corresponds to the mixing of mNAW whereas that at $\gamma 28.05 \sim \gamma 28.07$ is due to the mixing between AIW and DW. The sum of the reduction and formation of water is nearly zero at most of the fronts, and the slight imbalance in the volume flux can be attributed to the assumption that the vertical velocity below the lowest defined neutral surface $(\gamma 28.07)$ is zero. A notable feature at SB is that the highest divergence found in the lowest layer, exceeds the negative divergence at layers above (excess of $123 \mathrm{~m} /$ day, 

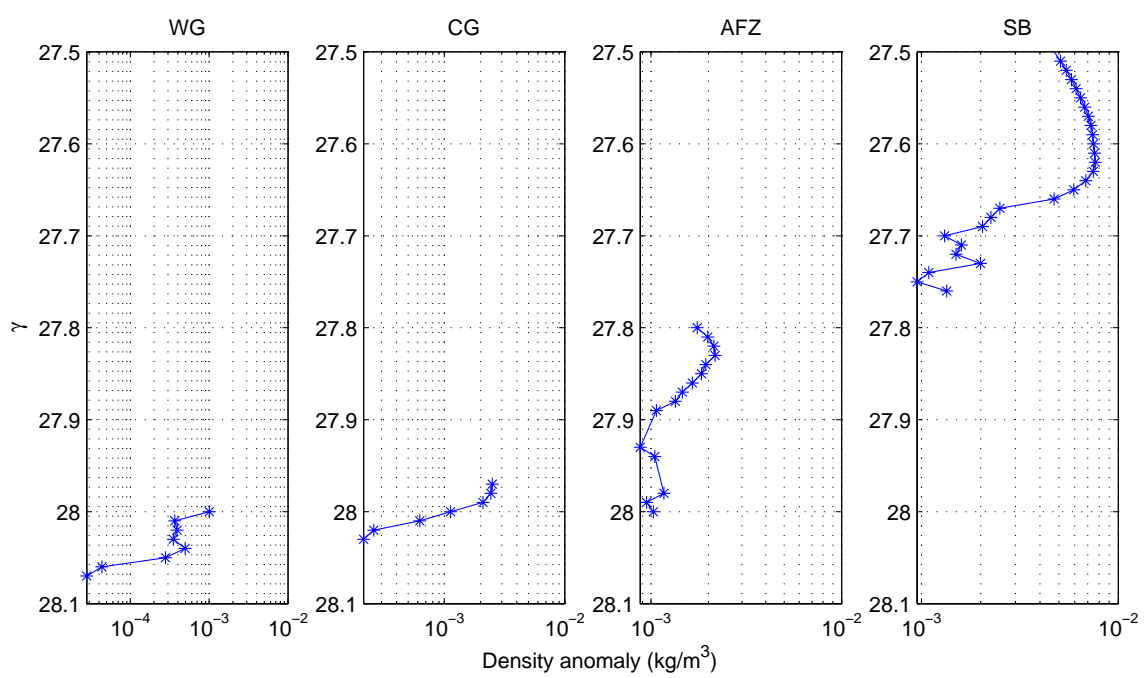

Fig. 11. Density anomaly estimated from the difference between averaged in situ density of source water and in situ density of the mixed water.

$\sim 0.0014 \mathrm{~m} / \mathrm{s}$ ). The lowest neutral surface reaches the ocean bottom at SB and the positive velocity divergence implies that the dense water which is produced sinks to the deep parts of the Greenland Basin.

The water mass formation rate at each frontal area is calculated by multiplying the frontal area with the velocity divergence. With our assumption of a $1 \mathrm{~km}$ meridional extent to the front, as discussed above, the lowest layer water mass formation rate is $0.18 \mathrm{~Sv}\left(=0.0031[\mathrm{~m} / \mathrm{s}] \times 59.4\left[\mathrm{~km}^{2}\right]\right)$ at $\mathrm{SB}$, and the net water mass formation rate is estimated to $0.085 \mathrm{~Sv}$. About half the water volume produced in the lowest layer sinks into the deep water. The water mass modification rates at the lowest layers in three groups are estimated to $0.15 \mathrm{~Sv}\left(=0.0013[\mathrm{~m} / \mathrm{s}] \times 116.4\left[\mathrm{~km}^{2}\right]\right), 0.31 \mathrm{~Sv}$, and $0.32 \mathrm{~Sv}$, respectively. The maximum volume increase seen in the second and third groups are twice that of the first group indicating that mNAW is more effective than NAW in producing denser water. At CG the modification rate at the lowest layer is $0.10 \mathrm{~Sv}\left(=0.0018[\mathrm{~m} / \mathrm{s}] \times 57.5\left[\mathrm{~km}^{2}\right]\right)$. The resulting admixture at CG is mNAW, though its temperature decreases with depth and its water property becomes closer to AIW in the lower layer (Fig. 8). At WG the mixed water type is DW in the lowest layer and the formation rate at this layer is $0.20 \mathrm{~Sv}$ $\left(=0.0014[\mathrm{~m} / \mathrm{s}] \times 143.8\left[\mathrm{~km}^{2}\right]\right)$.

\subsection{Density gain due to cabbeling process}

The mean in situ density of the source waters is compared with the mixed water in situ density at a neutral surface and the difference between them is plotted in Fig. 11. The increase of density anomaly is proportional to the velocity magnitude in the upper layers at $\mathrm{SB}$, and it reaches maximum at $\gamma 27.62$ with the value of $7.6 \times 10^{-3} \mathrm{~kg} / \mathrm{m}^{3}$. Below $\gamma 27.67$ the density anomaly decreases significantly to the bottom.
Table 4. Density gain at each front and the potential density of the mixed water in the lowest layer.

\begin{tabular}{lll}
\hline Front & $\begin{array}{l}\text { Net density gain } \\
\left(\times 10^{-3} \mathrm{~kg} / \mathrm{m}^{3}\right)\end{array}$ & $\begin{array}{l}\text { Mixed water density } \\
\text { in the lowest layer }\left(\sigma_{\theta}\right)\end{array}$ \\
\hline SB & 4.7 & 27.747 \\
AFZ & 1.5 & 27.963 \\
CG & 1.3 & 28.022 \\
WG & 0.4 & 28.066 \\
\hline
\end{tabular}

The density anomaly tends to decrease with depth at the other fronts. At AFZ, the density anomaly in the first group (above $\gamma 27.90$, NAW mixing) is slightly higher than that in the second and third groups (below $\gamma 27.90$, mNAW mixing) even though the velocity in the second/third groups is higher than in the first group. The density anomaly decrease with depth is more apparent at CG and WG. The density of the lower layer is higher than that in the upper layers and the mixing of denser water leads to a smaller density anomaly whereas the mixing between NAW and BIW is most effective in increasing the water density.

The net density gain at each frontal column is defined here as the mean value of the density anomaly through the layers. The density gain at SB is the highest with $4.7 \times 10^{-3} \mathrm{~kg} / \mathrm{m}^{3}$ and the lowest density gain is at WG with $0.4 \times 10^{-3} \mathrm{~kg} / \mathrm{m}^{3}$ (Table 4). Conversely, the potential density of the mixed water in the lowest layer is the highest at WG $\left(\sigma_{\theta}=28.07\right)$ and it is the lowest at $\mathrm{SB}\left(\sigma_{\theta}=27.75\right.$, Table 4$)$. 


\section{Discussion}

The water mass modification rate in Sect. 4.2 was presented under the assumption that the meridional length is $1 \mathrm{~km}$. The realistic meridional length of the fronts can be several kilometres, especially at SB and AFZ where the front extends along the northward Atlantic flow in the Nordic Seas. Here we discuss the realistic size of the frontal area and the associated water transformation.

Most of the active cabbeling spots are observed between two or three CTD stations (Fig. 6). The mean distance between CTD stations is $16.3 \mathrm{~km}$, therefore, the zonal length of the active cabbeling area can be $16.3 \mathrm{~km} \sim 22.6 \mathrm{~km}$. For the case of SB, the most vigorous mixing spots are found between two CTD stations in the eastern part of the front, and thus $\sim 16.3 \mathrm{~km}$ can be more realistic for the zonal length. SB is a part of the front formed along the Spitsbergen Bank in the Barents Sea and the location of BIW (or SBW according to Loeng, 1990) is confined to the Spitsbergen Bank. Bear Island is a tip of the Spitsbergen Bank, and thus the meridional length of SB can be thought as the length of the Bear Island $(\sim 20 \mathrm{~km})$. From this horizontal area $(16.3 \mathrm{~km} \times 20 \mathrm{~km})$ the water mass formation rate at the lowest layer is estimated to $1.0 \mathrm{~Sv}$.

The Arctic Frontal Zone consists of multiple frontal interfaces and active cabbeling spots were found at two front interfaces, B and C. A sharp frontal interface can be narrow, and here the zonal length is presumed to be the length between CTD observations, $16.3 \mathrm{~km}$. The zonal length of the two interfaces is, therefore, about $30 \mathrm{~km}$. The meridional extent of the Arctic Frontal Zone can be equivalent to that of the Greenland Basin (ca. $500 \mathrm{~km}$ ), though cabbeling would not occur at such high magnitude along the entire Arctic Frontal Zone. If the meridional length is taken as $100 \mathrm{~km}$, then the water mass formation in the Arctic Frontal Zone is estimated as $8.1 \mathrm{~Sv}$. In summer 2006, four frontal interfaces, A, B, C and $\mathrm{D}$, are evident, but active cabbeling is detected only at $\mathrm{B}$ and C. High buoyancy gradient suppresses the vertical velocity, and thus cabbeling cannot induce high velocity at interfaces $\mathrm{A}$ and $\mathrm{D}$, which are located in the upper stratified layer. This implies that cabbeling induced velocity becomes more significant when the buoyancy barrier is weakened in winter time. If the frontal interfaces A and D can cause a comparable amount of water modification as at $\mathrm{B}$ and $\mathrm{C}$ in winter, then the net water transformation at AFZ may increase considerably in winter.

The central Greenland Sea is the area of no clear front. From Fig. 6 the reasonable zonal length is three CTD stations, ca. $30 \mathrm{~km}$. If the mixing area can be estimated as a circle in the central gyre, then the active cabbeling area is presumed to be $15^{2} \pi \mathrm{km}^{2}$. With this horizontal area the water mass formation rate is estimated to $1.3 \mathrm{~Sv}$.

In the western part of the Greenland Sea the re-circulated NAW can form a weak front with the water of the interior of the Basin. The length of a weak front is larger than that of a sharp front and the meridional extent would be less significant than that found on the eastern side of the Greenland Sea. It is difficult to specify a reasonable horizontal area. Taking the area as $20 \mathrm{~km} \times 20 \mathrm{~km}$, the transformation is estimated to be $\sim 0.56 \mathrm{~Sv}$. It is notable that the mixed water density was the highest at WG. Table 2 shows that DW and other waters comprising $30 \%$ of the total volume determine the overall density of the Greenland Basin, and hence the volume increase of denser waters contributes directly to maintaining the density contrast between the Greenland Basin and the surrounding basins.

Although the water mass formation rates estimated above include a large uncertainty, most of the estimated water mass modification rates are one order higher than the renewal rate of intermediate water ( 0.1 to $0.2 \mathrm{~Sv}$, Karstensen et al., 2005) in the Greenland Sea. This indicates that cabbeling could play an important role in the transformation of water masses in the Greenland Basin. The increase of water volume in the intermediate layer causes the change of the thickness of the intermediate layer leading to a decrease in potential energy. The variation in the layer thickness controls the speed of the overflow (Whitehead, 1998), and so cabbeling might therefore affect the overflow velocity.

A remarkable feature of SB is the excess water production. Based on the horizontal area discussed above, the transport is $0.45 \mathrm{~Sv}$. This is one order higher than the brine water overflow from Storfjorden in the north of Bear Island $(0.06 \mathrm{~Sv}$, Skogseth et al., 2008). The brine water formation occurs only in winter whereas cabbeling at SB is expected to occur throughout the year since BIW and NAW are present throughout the year. Even though the influence of these transports on the buoyancy of the Greenland Basin has not yet been determined, the cabbeling-induced transport at SB supplies more water to the Greenland Basin, and so could have more impact on hydrographic change in the Greenland basin. In addition, the active cabbeling spots at SB form a columnar structure that may act as a transport pipe, transporting the surface water to the bottom. The surface water in the Barents Sea is rich in inorganic carbon (Omar et al., 2003) and the conversion of BIW in Barents Sea Opening may transport high $p \mathrm{CO}_{2}$ water into the deep Greenland Basin.

Acknowledgements. The present paper was supported by the EU through IP CARBOOCEAN (511176-2) and the Norwegian Research Council through its International Polar Year programme and the project iAOOS Norway - Closing the Loop (grant number 176096/S30) - http://www.iaoos.no/.

We thank to I. Fer and P. M. Haugan for comments on earlier versions of the manuscript.

Edited by: M. Hecht 


\section{References}

Akitomo, K.: Open-ocean deep convection due to thermobaricity 1. Scaling argument, J. Geophys., Res. 104(C3), 5225-5234, 1999.

Bönisch, G., Blindheim, J., Bullister, J., Schlosser, P., and Wallace, D.: Long-term trends of temperature, salinity, density and transient tracers in the central Greenland Sea, J. Geophys. Res., 102, 18553-18571, 1997.

Budéus, G., Schneider, W., and Krause, G. : Winter convective events and bottom water warming in the Greenland Sea, J. Geophys. Res., 103(C9), 18513-18527, 1998.

Clarke, R., Swift, J., Reid, J., and Kolterman, K. : The formation of Greenland Sea Deep Water: Double Diffusion or deep convection?, Deep-Sea Res., 37, 1385-1424, 1990.

Cottier, F. R. and Venables, E. J.: On the double-diffusive and cabbeling environment of the Arctic Front, West Spitsbergen, Polar Res., 26, 152-159, 2007.

Garrett, C. and Horne, E.: Frontal circulation due to cabbeling and Double diffusion, J. Geophys. Res., 83(C9), 4651-4656, 1978.

Gill, A. E. : Atmosphere-ocean dynamics, Academic Press, 1982.

Gordon, A. L., Georgi, D. T., and Taylor, H. W. : Antarctic polar front zone in the western Scotia Sea, J. Phys. Oceanogr., 7, 309_ 328, 1977.

Hansen, B. and Østerhus, S.: North Atlantic-Nordic Seas exchanges, Prog. Oceanogr., 45, 109-208, 2000.

Horne, E. P. W.: Interleaving at the subsurface front in the slope water off Nova Scotia, J. Geophys. Res., 83(C7), 3659-3671, 1978.

Jansen, E. and Opheim, V. (Eds.): European Subpolar Ocean Program (ESOP-II), The thermohaline circulation in the Greenland Sea-Final scientific report, contract MAS3-CT95-0015, Eur. Union, Brussels, 1999.

Karstensen, J., Schlosser, P., Wallace, D. W. R., Bullister, J. L., and Blindeheim, J.: Water mass transformation in the Greenland Sea during the 1990s, J. Geophys. Res., 110, C07002, doi:10.1029/2004JC002510, 2005.

Loeng, H.: Features of the physical oceanographi conditions of the Barents, Sea. Polar Res., 10(1), 5-18, 1990.

Marsh, R.: Cabbeling due to isopycnal mixing in isopycnic coordinate models, J. Phys. Oceanogr., 30, 1757-1775, 2000.

McDougall, T. J.: Thermobaricity, cabbeling and water mass conversion, J. Geophys. Res., 92(C5), 5448-5464, 1987a.

McDougall, T. J.: Neutral surface, J. Phys. Oceanogr., 17, 19501964, 1987b.

McDougall, T. J.: The relative roles of diapycnal and isopycnal mixing on subsurface water mass conversion, J. Phys. Oceanogr., 14, 1577-1589, 1984.
Messias, M.-J., Watson, A. T., Johannessen, T., Oliver, K. I. C., Olsson, K. A., Fogelqvist, E., Olafsson, J., Bacaon, S., Balle, J., Balle, N., Bergman, N., Budéus, G., Danielsen, M., Gascard, J.-C., Jeansson, E., Olafsdottir, S. R., Simonsen, K., Tauhua, T., Van Scoy, K., and Ledwell, J. R.: The Greenland Sea Tracer Experiment 1996-2002: horizontal mixing and transport of Greenland Sea Intermediate Water, Prog. Oceanogr., 78(1), 85-105, doi:10.1016/j.pocean.2007.06.005, 2007.

Munk, W. H. and Wunch, C.: Abyssal Recipes II: energetics of tidal and wind mixing, Deep-Sea Res., 45, 1977-2010, 1998.

Omar, A., Johannessen, T., Kaltin, S., and Olsen, A.: Anthropogenic increase of oceanic $p \mathrm{CO}_{2}$ in the Barents Sea surface water, J. Geophys. Res., 108(C12), 388 , doi:10.1029/2002JC001628, 2003.

Skogseth, R., Smedrud, L. H., Nilsen, F., and Fer, I. : Observations of hydrography and downflow of brine-enriched shelf water in the Storfjorden polynya, Svalbard, J. Geophys. Res., 113, C08049, doi:10.1029/2007JC004452, 2008.

Sundfjord, A., Fer, I., Kasajima, Y., and Svendsen, H. : Observations of turbulent mixing and hydrography in the marginal ice zone of the Barents Sea, J. Geophys. Res., 112, C05008, doi:101029/2006JC003524, 2007.

Swift, J. H. and Aagaard, K. : Seasonal transitions and water mass formation in the Iceland and Greenland seas, Deep-Sea Res., 28A(10), 1107-1129, 1981.

Talley, L. and Yun, J. Y.: Role of cabbeling and double diffusion in setting the density of the North Pacific intermediate water salinity minimum, J. Phys. Oceanogr., 31, 1538-1549, 2001.

van Aken, H., Budéus, G., and Hahnel, M.: The anatomy of the Arctic Frontal Zone in the Greenland Sea, J. Geophys. Res., 100(C8), 15999-16014, 1995.

van Aken, H. M., Quadfasel, D., and Warpakowski, A.: The Arctic front in the Greenland Sea during February 1989: Hydrographyc and biological observations, J. Geophys. Res., 96, 4739-4750, 1991.

Walin, G.: On the relation between sea-surface heat flow and thermal circulation in the ocean, Tellus, 34, 187-195, 1982.

Whitehead, J. A.: Topographic control of oceanic flows in deep passage and straits, Rev. Geophys., 36(3), 423-440, 1998.

You, Y.: Dianeutral mixing in the thermocline of the Indian Ocean, Deep-Sea Res. Pt. I, 43, 291-320, 1996.

You, Y.: Dianeutral mixing, transformation and transformation and transport of Antarctic Intermediate Water in the South Atlantic Ocean, Deep-Sea Res. Pt. II, 46, 393-435, 1999. 